\title{
Gestão de Recursos Humanos e Comprometimento Organizacional: estudo de caso nas Unidades de Saúde Familiar
}

\author{
Cláudia Silva \\ Agência para a Modernização Administrativa, I.P. (AMA) \\ claudiaraquelro@hotmail.com \\ João Pedro Cordeiro \\ Escola Superior de Ciências Empresariais \\ Instituto Politécnico de Setúbal \\ joao.cordeiro@esce.ips.pt
}

\section{Resumo}

Este estudo tem como objetivo estudar e analisar a relação entre as práticas de gestão de recursos humanos e o comprometimento organizacional dos profissionais das Unidades de Saúde Familiar (USF). Como objetivos específicos pretende-se analisar: as práticas de gestão de recursos humanos das USF, os níveis de comprometimento organizacional dos profissionais das várias USF tendo em conta os diferentes níveis remuneratórios (modelo A e modelo B) e a relação entre as variáveis das práticas de gestão de recursos humanos e o comprometimento organizacional. Em termos metodológicos, para analisar as práticas de gestão de recursos humanos aplicou-se um inquérito por questionário, testado por Esteves (2008). Para analisar o comprometimento organizacional aplicou-se um inquérito por questionário referente ao modelo de Meyer e Allen (1997), adaptado à realidade portuguesa por Nascimento (2008). A amostra é constituída por 55 profissionais. Os resultados encontram-se, de uma forma geral, de acordo com alguns estudos empíricos e permitem concluir que existem correlações positivas entre as práticas de gestão de recursos humanos e o comprometimento organizacional. Constatou-se, também, que são sobretudo os profissionais das USF, modelo B, os que estão mais comprometidos com a organização; que os profissionais de ambos os modelos de USF, modelo A e modelo B, apresentam médias mais elevadas no comprometimento afetivo e no comprometimento calculista, quando comparados com o comprometimento normativo; e que as variáveis sociodemográficas não revelam possuir correlações fortes com o comprometimento organizacional. Conclui-se, assim, que os profissionais das USF possuem diferentes níveis de comprometimento organizacional, os quais são diferentemente ancorados pelas práticas de gestão de recursos humanos e pelos modelos de gestão preconizados (USF modelo A e USF modelo B). Este estudo permite refletir sobre a inter-relação entre as práticas de gestão de recursos humanos e o comprometimento organizacional, auxiliando a formulação de novos modelos de gestão (USF) que contribuam para alcançar melhores performances. Contribuiu, assim, para aprofundar a compreensão e o interesse por este modelo de gestão, que se encontra em expansão, potencializando estudos futuros.

\section{Palavras-Chave:}

Práticas de Gestão de Recursos Humanos; Comprometimento Organizacional; Unidades de Saúde Familiar. 
VI Conferência de Investigação e Intervenção em Recursos Humanos (IIRH 2016).

ESCE/IPS, 18 e 19 de fevereiro de 2016. 